\title{
The factors that cause the misjudgement in questioned document examination: Extraneous marks and deteriorating factors
}

\author{
Ayşegül ŞEN YILMaZ \\ ORCID: 0000-0002-3180-7689 \\ Institute of Forensic Sciences and Legal Medicine \\ Istanbul University, Cerrahpasa, Turkey \\ ÖZge GenÇ SutLu \\ ORCID: 0000-0002-8863-9823 \\ Institute of Forensic Sciences and Legal Medicine \\ Istanbul University, Cerrahpasa, Turkey \\ FARUK AŞICIOĞLU \\ ORCID: 0000-0003-1691-6171 \\ Institute of Forensic Sciences and Legal Medicine \\ Istanbul University, Cerrahpasa, Turkey
}

\begin{abstract}
Artificial defects on the documents can be classified into two categories: extraneous marks and deteriorating factors. Identifying and categorizing artificial defects of the examined document and determining some critical unforeseen details are the aims of
\end{abstract}


this study. Real case samples were collected from our archive and examined. It was found that 41 out of total 100 cases include either extraneous marks or deteriorating factors.

Keywords: questioned document examination, defects, document alteration, handwriting analysis, signature analysis

\section{Background}

In various cases, documents may be changed during the preparation or after their completion without attempts on anyone's part to perpetrate fraud. These situations are not new or challenging problems for questioned document examiners. Changes in the documents may cause misjudgement in terms of identifying questioned signature or handwriting and appear in different forms and shapes, which can be named as "artificial defects."1

We classified artificial defects into two groups: extraneous marks and deteriorating factors.

Extraneous marks can be categorized into: ink leakage from the pen; a trace formed because the pen did not write correctly during the first attempt; marks such as a cross or dots formed by another person for the purpose of pointing out the signature section on the document; masking the signature partially by stamp ink; stroke remnants from the previous person who halted their signature because of a wrong location; and overlapping signatures due to signing in a limited space.

On the other hand, deteriorating factors can be categorized into: partial loss of pen stroke in signature or handwriting on the folded or cut part of the paper; staple and/or puncher holes on the signed or written part of the document; superficial abrasion or tearing of the paper due to sloppy handling during the chain of evidence delivery; and attrition of the questioned document touched with adhesive materials such as envelope glue or upon contact with liquid or oil.

In his book, Hilton mentioned stains, which are among the artificial defects that disfigure the document. Some types of stains leave the document readable, but others obliterate its portions or seriously reduce the performance of document examination. He also mentioned that intersecting

${ }^{1}$ R.N. Totty, D. Baxendale, "Defect marks and the identification of photocopying machines", Journal of the Forensic Science Society 21, 1981, no. 1, pp. 23-30. 
writing strokes may have distinctive patterns, depending upon the order of writing, the lapse of time between the two writings, the density of the two strokes, and the kind of inks, writing instruments, and paper used. Sometimes pen ink may create a stain on the document - it can overflow on the paper, spread discernibly into the adjacent paper fibres, and make a shade on some part of the questioned handwriting or signature. ${ }^{2}$

On some occasions, ambient humidity may be destructive for the documents which are not preserved under appropriate conditions. If the documents are exposed to moisture, the paper may adhere to itself. Penetration by the liquid may cause the ink to run or itself damage the paper due to adhesion. ${ }^{3}$

On other occasions, small deposits or traces of many different substances may be found on documents and may aid in reconstructing their history. Many of these are placed there purely through chance contacts with foreign objects during the preparation and subsequent handling or storing of the document. ${ }^{4}$

Partial loss of pen strokes may occur due to erasures of signature or handwriting. These can be either chemical or mechanical. The trace of chemical erasures can be found when the document is examined under UV light. In the case of mechanical erasure, such as with the traditional "rubber" eraser, an abrasive movement is made upon the writing to be erased. In many cases of standard writing materials, abrasion of the paper can be seen either with a microscope or a side light. However, some type of erasures and abrasions cannot be seen even under side light. ${ }^{5}$

Light exposure can also cause changes in the document in the aspect of paper or ink. Certain poorer quality synthetic dye inks and ballpoint pen inks, for instance, may fade due to long exposure to light, which can result in losing some important written parts of the document. Other types

2 O. Hilton, Scientific examination of questioned documents, Boca Raton, FL 1992 , pp. 111-114.

3 J. Levinson, Questioned documents: A lawyer's handbook, San Diego, CA 2001, pp. 137-142.

4 O. Hilton, op. cit.

5 J. Levinson, op. cit.; J.S. Kelly, B.S. Lindblom, Scientific examination of questioned documents, Boca Raton, FL 2006, pp. 319-336. 
of inks such as carbon and record typewriting inks remain virtually unchanged. ${ }^{6}$

In order to analyse degraded documents, various different methods such as lost part completion are digitally applied to visualize the lost part of the documents. However, the methods that make the missing part of the document visible do not always work well for the examiner. ${ }^{7}$

In this study, we had two goals. The first one was to identify and categorize the problems stemming from the examined document, and the second one - to highlight some critical unforeseen details and provide guidance to document examiners.

\section{Material methods}

Real case samples were collected from the Questioned Document Laboratory of Istanbul University, Cerrahpasa, Institute of Forensic Sciences and Legal Medicine.

A total of 100 even-numbered file cases were selected from the files that have been examined dated between January 2018 and August 2020. The images from these cases, which had been taken with VSC8000 (Foster \& Freeman, UK), were obtained from electronic archives of our laboratory.

These cases were examined independently by two different handwriting examiners at first. After that, if there was a contradiction between their decisions, they evaluated and discussed their opinions interactively, and it was decided which of the two types described above the cases fit into.

\section{Results and discussion}

It was found that 41 out of total 100 cases include either extraneous marks or deteriorating factors. The results of extraneous marks and de-

6 O. Hilton, op. cit.

7 M. Diem, R. Sablatnig, "Recognition of degraded handwritten characters using local features", 10th International Conference on Document Analysis and Recognition, July 26-29 2009, Barcelona, Spain, pp. 221-225. 
The factors that cause the misjudgement in questioned document examination 157

teriorating factors' distribution are listed in Table 1 and Table 2. These tables also contain images of the defects.

Table 1. Distribution of artificial defects in the aspects of extraneous marks

\begin{tabular}{|c|c|c|}
\hline $\begin{array}{c}\text { Number } \\
\text { (percentage) }\end{array}$ & Extraneous marks & Images \\
\hline $7(17.1 \%)$ & ink leakage from the pen & \\
\hline $9(22 \%)$ & $\begin{array}{l}\text { the trace formed because } \\
\text { the pen did not write } \\
\text { correctly during the first } \\
\text { attempt }\end{array}$ & \\
\hline $11(26.8 \%)$ & $\begin{array}{l}\text { marks such as a cross or } \\
\text { dots formed by another } \\
\text { person for the purpose of } \\
\text { pointing out the signature } \\
\text { section on the document }\end{array}$ & \\
\hline $5(12.2 \%)$ & $\begin{array}{l}\text { masking the signature } \\
\text { partially by stamp ink }\end{array}$ & \\
\hline $1(2.4 \%)$ & $\begin{array}{l}\text { stroke remnants from } \\
\text { the previous person who } \\
\text { halted their signature } \\
\text { because of wrong } \\
\text { location }\end{array}$ & \\
\hline $2(4.9 \%)$ & $\begin{array}{l}\text { overlapping signatures } \\
\text { due to signing in } \\
\text { a limited space }\end{array}$ & \\
\hline
\end{tabular}


Table 2. Distribution of artificial defects in the aspects of deteriorating factors

\begin{tabular}{|c|l|l|}
\hline $\begin{array}{c}\text { Number } \\
\text { (percentage) }\end{array}$ & \multicolumn{1}{c|}{$\begin{array}{c}\text { Deteriorating } \\
\text { factors }\end{array}$} \\
\hline $2(4.9 \%)$ & $\begin{array}{l}\text { partial loss of pen } \\
\text { stroke in signature } \\
\text { or handwriting on } \\
\text { the folded or cut } \\
\text { part of the paper }\end{array}$ \\
\hline $2(4.9 \%)$ & $\begin{array}{l}\text { puncher holes } \\
\text { on the signed or } \\
\text { written part of the } \\
\text { document }\end{array}$ \\
\hline $1(2.4 \%)$ & $\begin{array}{l}\text { staple and/or } \\
\text { of the paper due } \\
\text { to sloppy handling } \\
\text { during the chain of } \\
\text { evidence delivery }\end{array}$ \\
\hline $1(2.4 \%)$ & $\begin{array}{l}\text { strition of the } \\
\text { questioned } \\
\text { document upon } \\
\text { contact with } \\
\text { adhesive materials } \\
\text { such as envelope } \\
\text { glue }\end{array}$ \\
\hline
\end{tabular}

Extraneous marks are divided into two categories: as intentionally and unintentionally made according to our observations in this study. The first only applies in the case of a cross or dots marks formed by another person. The rest of the marks are carried out unintentionally.

Deteriorating factors, unlike the extraneous marks, cause deformation on the document. Four different types of these marks were found in our 
study. These are: partial loss of pen stroke in signature or handwriting on the folded part of the paper; staple and/or puncher holes on the signed or written part of the document; superficial abrasion or tearing of the paper due to sloppy handling during the chain of evidence delivery; and attrition of the questioned document upon contact with adhesive materials such as envelope glue.

The most frequently encountered defects are crosses or dots formed by another person for the purpose of pointing out the signature section on the document. In Turkey, voters' list and bank agreements can be marked by a pen to show where to sign. Sometimes, those marks can be mistaken for part of signature. It can be confusing for the examiner if there is a similar symbol in the original signature. This made it hard to identify whether those were a related personal habit or a marking done by someone else.

The rarest cases are: stroke remnants, superficial abrasion or tearing of the paper, and attrition of the questioned document because of adhesive materials. These situations can occur in different ways. Sometimes people stop signing when they realized they had signed on someone else's spot on the documents - however, that missing signature looks like a part of the other person's signature and stroke remnants may occur. In the second instance, when a document is folded without paying attention, the folding part can overlap the signature and cause it to lose some characteristics specific to the individual. Finally, when documents are not stored carefully, different inks or materials can mess up the signature - this can then be recognised as an additional character or hand movement, or it can mask a specific character.

As a result, the amount of artificial defects we came across in this study demonstrated to us several precautions which should be taken to minimise the effects on the judicial process. Firstly, the impact of defects should be included in the training program for the candidates who want to become questioned document experts. Secondly, experts should keep in mind the possibility of artificial defects, which may help them avoid the misinterpretation. For example, signs used for indicative purposes should not be mistakenly considered as symbols. Last but not least, law enforcement and the judicial justice personnel in charge of evidence delivery and document processing should be trained to avoid creating these types of effects. 


\section{References}

Diem M., Sablatnig R., "Recognition of degraded handwritten characters using local features", 10th International Conference on Document Analysis and Recognition, July 26-29 2009, Barcelona, Spain.

Hilton O., Scientific examination of questioned documents, Boca Raton, FL 1992.

Kelly J.S., Lindblom B.S., Scientific examination of questioned documents, Boca Raton, FL 2006.

Levinson J., Questioned documents: A lawyer's handbook, San Diego, CA 2001.

Totty R.N., Baxendale D., "Defect marks and the identification of photocopying machines", Journal of the Forensic Science Society 21, 1981, no. 1. 


\section{Information for the authors}

1. Please send electronic versions of your articles to the journal's editorial board to: Katedra Prawa Karnego Wykonawczego, Wydział Prawa, Administracji i Ekonomii UWr, ul. Uniwersytecka 22/26, 50-145 Wrocław or via e-mail to: kpkw@prawo.uni.wroc.pl.

2. All articles published in the Nowa Kodyfikacja Prawa Karnego [New Codification of Criminal Law] journal are peer-reviewed.

3. The reviewers' and editors' comments are sent to the authors, who are obliged to introduce the changes and make the corrections suggested to them.

4. The authors will be informed about whether their articles have been accepted for publication within 30 days via e-mails sent to the addresses provided by them.

5. Articles should be submitted as Word or RTF documents. Maximum article length: 40,000 characters including spaces.

6. Detailed information concerning text formatting and footnotes can be found on www.wuwr.com.pl under the "Dla Autorów" [For the Authors] tab.

7. Please provide a summary, key words and title of your article in English (up to 400 characters including spaces).

8. Wydawnictwo Uniwersytetu Wrocławskiego reserves the right to introduce editorial changes into the articles.

9. By submitting their articles to the journal's editorial board the authors state that they hold the copyright rights to the articles, that the articles are free from any defects of title and that they have not been previously published elsewhere in their entirety or in part nor have they been submitted to any other journal, and grant their consent, free of charge, to have their articles published in the Nowa Kodyfikacja Prawa Karnego journal and disseminated without any limitation as to the time and territory, including by marketing copies of the journal as well as making them available on the internet free of charge and in exchange for a fee.

10. The authors are obliged to make corrections to their articles within 7 days of receiving the relevant comments. A failure to make the corrections within the deadline signifies that the author agrees to have the article published in the form submitted for proofreading.

11. In order to ensure quality and reliability of its publications, the editorial board of the Nowa Kodyfikacja Prawa Karnego journal has implemented procedures counteracting "ghostwriting" and "guest authorship". In view of the above, all authors should submit a declaration in which they will reveal the contribution (in percentage terms) of the various individuals to the paper submitted, and provide information about the sources of its financing and any contribution of academic and research institutions, associations and other entities. Responsibility for the information provided lies with the author submitting the paper. A relevant declaration form can be found on nkp.wuwr.pl.

12. The authors do not receive any fee for their articles.

13. After an article has been published, its author receives one printed copy of Nowa Kodyfikacja Prawa Karnego free of charge. All articles made available by Wydawnictwo Uniwersytetu Wrocławskiego in PDF format can be found on www.cns.wuwr.pl. 